\title{
A tecnologia abrindo espaço para discussão e aprendizagem sobre Direitos Humanos no Ensino Médio
}

\section{Technology making room for discussion and learning about Human Rights in High School}

\author{
Rinara Granato Santos \\ Instituto Federal de Educação, Ciência e Tecnologia do Sudeste de Minas \\ rinaragranato@gmail.com \\ Natalino da Silva de Oliveira \\ Instituto Federal de Educação, Ciência e Tecnologia do Sudeste de Minas \\ natalino.oliveira@ifsudestemg.edu.br
}

\section{Resumo}

O ensino/aprendizagem sobre Direitos Humanos no ensino médio é um desafio constante tanto para os profissionais da educação quanto para os discentes. Uma das maiores dificuldades no processo de implementação da Educação em Direitos Humanos em todo ciclo escolar, do básico ao superior, reside na ausência de formação do docente, das diferentes áreas de conhecimento, no que tange aos conteúdos que substanciam a Educação em Direitos Humanos. Afinal, quais estratégias os docentes deveriam assumir para converter sua prática em um exercícios democrático? Como estimular o interesse dos estudantes? Este artigo se apropria dos estudos em educomunicação e de novas tecnologias como ferramentas que fomentem a discussão orientada sobre Direitos Humanos na escola, contribuindo para a formação de uma verdadeira cultura de paz, dentro e fora do espaço escolar.

Palavras-chave: Tecnologia. Direitos humanos. Ensino médio. Educomunicação.

\begin{abstract}
Human rights teaching / learning in high school is a constant challenge for both education professionals and students. One of the major difficulties in the implementation process of Human Rights Education throughout the school cycle, from basic to higher education, is the absence of teacher training in the different areas of knowledge regarding the contents that substantiate Human Rights Education. After all, what strategies should teachers take to convert their practice into a democratic exercise? How to stimulate student interest? This article appropriates studies in educommunication and new technologies as tools that promote a focused discussion about human rights in the school, contributing to
\end{abstract}




\section{ededucitec

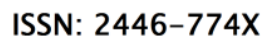

the formation of a true culture of peace, inside and outside the school space.

Key words: Technology. Human rights. Secondary education. Educommunication.

\section{Introdução}

Um dos maiores desafios no processo de implementação da Educação em Direitos Humanos em todo ciclo escolar, do básico ao superior, reside na ausência de formação do docente, das diferentes áreas de conhecimento, no que tange aos conteúdos que substanciam a Educação em Direitos Humanos, sendo este mais um dos muitos encargos atribuídos à escola, que cada vez mais é instada a resolver problemas sociais graves, neste caso, a intolerância e o ódio aos diferentes.

Este comprometimento com uma formação superior em todas as áreas, permeada por conhecimentos sobre Direitos Humanos daria fundamento teórico aos futuros professores de ensino médio que, munidos do conhecimento básico e histórico sobre o assunto, poderiam expandi-lo com naturalidade na educação básica, de forma transversal as suas áreas de atuação, fazendo com que a Escola ajude a promover na sociedade brasileira uma verdadeira cultura de Paz, "através de valores, atitudes e comportamentos que refletem o respeito à vida." (BRASIL, 2013, p.44).

Entretanto, na prática, a maioria dos professores da educação básica não teve acesso à apreensão dos conceitos e conhecimentos historicamente adquiridos sobre direitos humanos quando da sua própria formação docente. Como suplantar esta lacuna? A resposta pode estar no uso da tecnologia, buscando nos princípios da tecnologia educativa técnicas de apresentação hipermidiática do conhecimento, através de materiais áudio visuais dos mais diversos formatos que, utilizando uma linguagem que dialogue com a geração hiperconectada e tecnológica composta por alunos desta faixa etária, promova uma formação em temas de Direitos Humanos, instruindo simultaneamente alunos e professores

\section{A escola como promotora de uma cultura de paz}

A escola é constantemente requisitada como peça fundamental em um processo expansionista de uma verdadeira cultura de paz na sociedade, traduzindo esta cultura em um respeito às diferenças, na promoção da igualdade, da liberdade $e$ da tolerância, requisitos estruturantes na implementação dos Direitos Humanos em qualquer agrupamento social. Entretanto, é um espaço pouco aparelhado para introduzir noções de Direitos Humanos de uma forma que realmente incite os alunos, na sua maioria jovens e adolescentes, ao aprofundamento do tema, de forma a interligá-lo ao cotidiano dos aprendizes e às disciplinas curriculares a eles ministradas.

Além disso, o processo educacional brasileiro é bastante pasteurizado, como em boa parte do Ocidente, e, sendo pouco diversificado, apresenta dificuldades em lidar com a heterogeneidade dos temas que lhe são conexos. 


\section{Educitec \\ ISSN: $2446-774 X$}

No caso da educação, promove-se uma política de universalização da escolarização, todos são chamados a participar do sistema escolar, mas sem que se coloque em questão o caráter monocultural presente na sua dinâmica, tanto no que se refere aos conteúdos do currículo quanto às relações entre os diferentes atores, as estratégias utilizadas nas salas de aula, aos valores privilegiados etc. (CANDAU, 2008, p. 50).

No Brasil, desde 2004, há previsão para que a educação básica caminhe de forma Integrada à educação profissional, o que significa, na prática, a simples junção em um mesmo currículo e matrícula das disciplinas dos dois campos do conhecimento. Os teóricos da educação brasileira defendem, no entanto, uma educação, ainda que a puramente propedêutica, que caminhe de forma integral e não simplesmente integrada, ou seja, que proporcione aos alunos um conhecimento conjunto dos conteúdos presentes na educação propedêutica e a apropriação dos conceitos e conhecimentos históricos do mundo do trabalho.

Ao defenderem a proposta de Ensino Médio Integrado, resgatam fundamentos filosóficos, epistemológicos e pedagógicos da concepção de educação politécnica e omnilateral e de escola unitária baseado no programa de educação de Marx e Engels e de Gramsci. Tais fundamentos convergem para uma concepção de currículo integrado, cuja formulação incorpora contribuições já existentes sobre o tema, mas pressupõem a possibilidade de se pensar um currículo convergente com os propósitos da formação integrada - formação do sujeito em múltiplas dimensões, portanto, omnilateral - e da superação da dualidade estrutural da sociedade e da educação brasileiras. (RAMOS, 2011, p. 775/776)

Nesta esteira, falar em formação omnilateral, ou em formação do sujeito em suas múltiplas dimensões, compreende um processo formativo que contemple mais que a formação propedêutica ou que a apreensão dos conhecimentos e práticas do mundo do trabalho, trata-se de pleitear uma formação também, humana e social; único caminho para se almejar verdadeiramente a cidadania, direito constitucional do povo brasileiro.

Se a existência humana não é garantida pela natureza, não é uma dádiva natural, mas tem de ser produzida pelos próprios homens, sendo, pois, um produto do trabalho, isso significa que o homem não nasce homem. Ele forma-se homem. Ele necessita aprender a ser homem, precisa aprender a produzir sua própria existência. Portanto, a produção do homem é, ao mesmo tempo, a formação do homem, isto é, um processo educativo. A origem da educação coincide, então com a origem do homem mesmo (SAVIANI, 2007, p. 154).

Saviani (2007) explicita o processo educativo já como o próprio processo de formação do homem, atribuindo à escola a responsabilidade pela educação, em um sonhado modelo de construção multifacetada deste aluno, que envolva trabalho, ciência e cultura. Esta difícil união entre os saberes torna-se ainda mais distante da formação que atualmente ofertamos, isto em grande parte, por culpa do modelo educacional por nós adotado, segundo Morin:

A escola primária nos ensinam a isolar os objetos (de seu meio ambiente), a separar as disciplinas (em vez de reconhecer suas correlações), a dissociar os problemas, em vez de reunir e integrar. Obrigam-nos a reduzir o complexo ao simples, isto é, a separar o que está ligado; a decompor, e não a recompor; e a eliminar tudo que causa 


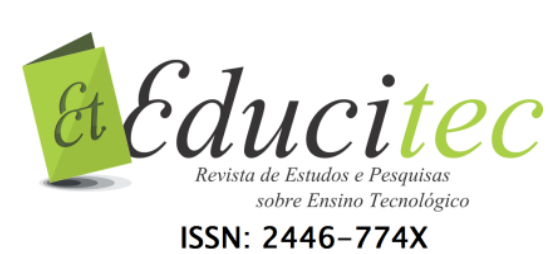

desordens ou contradições em nosso entendimento (MORIN, 2003, p. $15)$.

Uma escola que segrega, desde conceitos à pessoas, não tem condições de promover uma formação humana e cidadã plena, no entanto, uma escola capaz de ligar o cotidiano do aluno, o entorno da sua comunidade escolar, fazê-lo sentir-se parte do meio social e reconhecer as opressões sobre as quais aquele indivíduo é sujeito, enfim, uma escola capaz de promover na educação básica um olhar multidimensional que una o trabalho, a ciência e a cultura como pilares desta formação, aproxima-se da formação omnilateralidade sonhada por Saviani, Ramos e tantos outros teóricos da educação.

\begin{abstract}
Voltaremos nossa atenção para os sentidos do ensino médio e a necessidade de educação básica vincular-se à prática social por meio das dimensões fundamentais da vida: o trabalho, a ciência e a cultura. Destacaremos a histórica subordinação do ensino médio a projetos que estão "fora dele": o mercado de trabalho e o vestibular. Contrapomos a essa tendência o fato de que os sujeitos do ensino médio têm uma vida, uma história e uma cultura, que configuram necessidades diferenciadas, mas também direitos universais. Nesse ponto, faremos, mais uma vez, a defesa de um projeto de ensino médio que integre trabalho, ciência e cultura, na perspectiva de uma formação unitária, politécnica e omnilateral. (RAMOS, 2010, p. 43)
\end{abstract}

Neste ponto, ao menos em termos legais, a legislação brasileira determinou diferentes obrigações no sentido de se alcançar uma formação básica verdadeiramente emancipatória. A Lei de Diretrizes e Bases da Educação, em 2014, reconhecendo a importância do estudo dos Direitos Humanos na etapa básica acresce ao seu texto a seguinte determinação, que foi mantida na reforma de 2017:

Art. 26. Os currículos da educação infantil, do ensino fundamental e do ensino médio devem ter base nacional comum, a ser complementada, em cada sistema de ensino e em cada estabelecimento escolar, por uma parte diversificada, exigida pelas características regionais e locais da sociedade, da cultura, da economia e dos educandos (Redação dada pela Lei n. 12.796, de 2013).

$\S 9^{\circ}$ Conteúdos relativos aos direitos humanos e à prevenção de todas as formas de violência contra a criança e o adolescente serão incluídos, como temas transversais, nos currículos escolares de que trata o caput deste artigo, tendo como diretriz a Lei n. 8.069, de 13 de julho de 1990 (Estatuto da Criança e do Adolescente), observada a produção e distribuição de material didático adequado (Incluído pela Lei no 13.010, de 2014). (BRASIL, 1996 e 2017) (grifo nosso).

Entender a difusão dos conhecimentos de Direitos Humanos na educação básica como única medida capaz de aproximar a educação ofertada no Brasil a uma educação que forme sujeitos - na sua integralidade - seria simplificar sobremaneira a problemática do campo educacional brasileiro. No entanto, necessário reconhecer o significado positivo da expansão dos conhecimentos sobre direitos humanos, conduzido pelas escolas brasileiras, sendo apenas mais uma das necessárias contribuições na difícil tarefa de dar significação à escolarização básica do país. Essa constatação nos obriga a refletir sobre que conceitos de "Direitos Humanos" nós queremos difundir entre os alunos. 


\title{
Ededucitec
}

ISSN: $2446-774 X$

Nem a ultrapassada formação "moral e cívica" dos tempos da ditadura militar brasileira, nem a equivocada associação entre Direitos Humanos e a "defesa de bandidos", ou o simples doutrinamento dos "direitos e deveres" do aluno, condizem com os desafios que os Direitos Humanos apresentem-se na sua expansão através da escola. O norte definido pelo estado brasileiro para este processo escolar, consubstancia-se na formação integral, e esta sinalizado nas Diretrizes Curriculares da Educação em Direitos Humanos, de 2013, segundo a qual:

No aspecto cognitivo destaca-se a importância da apreensão dos conceitos e conhecimentos historicamente construídos sobre direitos humanos, uma vez que o sujeito só poderá sentir-se efetivamente consciente de seus direitos se souber quais são esses direitos, como surgiram, como se desenvolveram, que lutas históricas foram travadas no processo de construção e fortalecimento desses direitos (BRASIL, 2013, p. 45-46).

Na prática escolar, o norte ofertado pelas diretrizes curriculares da Educação em Direitos Humanos está em sintonia com o pensamento de Marise Ramos (2010), quando a teórica aprofunda-se na formação integral do sujeito e desfaz, definitivamente, a antiga crença de que este modelo formativo só preocupavase em unir o mundo do trabalho ao universo propedêutico academista. Destacando a formação humanística, a cultura e a tecnologia como lugares de importância na construção/transição de aluno a Sujeito de cidadania. Fica claro que esta árdua travessia não pode ser feita sem ofertar ao aluno uma compreensão real da sociedade na qual ele está inserido, para isto, discutir o capitalismo, o liberalismo, a educação, as desigualdades, as liberdades, entre tantas outras questões que compõe o leque de Direitos Humanos é imprescindível.

\begin{abstract}
O conceito de integração, entretanto, vai além da forma. Não se trata de somar currículos e/ou as cargas horarias referentes ao ensino médio e às habilitações profissionais, mas sim de relacionar, internamente à organização curricular e do desenvolvimento do processo de ensino-aprendizagem, conhecimentos gerais e específicos; cultura e trabalho; humanismo e tecnologia.(...) Um projeto de ensino médio integrado ao ensino técnico tendo como eixos de trabalho, a ciência e cultura, deve buscar superar o histórico conflito existente em torno do papel da escola, de formar para a cidadania ou para o trabalho produtivo e, assim, o dilema de um currículo voltado para as humanidades ou para a ciência e tecnologia, bem como a dicotomia entre conteúdos e competências. Afinal, os conteúdos do ensino não são conhecimentos abstratos desprovidos de historicidade, nem insumos para o desenvolvimento de competências; ao contrário, trata-se de conhecimentos construídos historicamente e que se constituem, para o trabalhador, em pressupostos a partir dos quais se podem construir novos conhecimentos no processo de investigação e compreensão do real (RAMOS, 2010, p. 51-52).
\end{abstract}

Neste ponto, é importante compreender que há muitas lutas sociais travada em todos os pontos do globo, desde longo tempo, com intuito de alcançarmos cada pequeno avanço em um leque normativo que nos proteja do "mais forte", que ao final é o Estado. Este conhecimento é a base dos Direitos Humanos, por isto, a transversalidade do tema deve permear toda a formação básica, com maior 


\section{Eteducitec \\ ISSN: $2446-774 X$}

incisão no Ensino Médio, só assim poderemos exercitar a formação verdadeiramente integral.

\section{Teorias contemporâneas da aprendizagem e o ensino/aprendizagem em Direitos Humanos}

Fomentar e descortinar o diálogo sobre Direitos Humanos na Escola, especialmente na educação básica não é tarefa fácil, a despeito da lei prescrever a inserção destes temas na rotina escolar, a falta de formação específica do docente e o nível de agressividade presente na coletividade em geral, quando temas afetos a proteção humana são abordados são alguns dos entrave mais comuns que dificultam a abordagem deste conteúdo na educação básica, no entanto, suplantadas estas adversidades, quando o professor permite e orienta o diálogo entre seus alunos percebe que a controvérsia e os diferentes pontos de vista é que efetivamente consubstanciam o aprendizado.

Neste sentido, a proposta é chegar a um entendimento que promova a tolerância e pacifique os ódios, professores e alunos aprendendo ao mesmo tempo que ensinam, ensinando enquanto aprendem. O exercício de refletir sobre alguns dos temas mais relevantes e atuais dos direitos humanos, através de conteúdos menos formais que os regulares textos acadêmicos e ainda, utilizando uma linguagem tecnológica, tem maiores chances de despertar o interesse de professores e alunos, incentivando-os a construírem uma rede de conhecimentos que respondam suas dívidas sobre direitos humanos através da lógica, da contextualização social, da observação de figuras púbicas que inspiram, enfim, levar a escola às redes sociais, onde estão nossos alunos, em busca de promover uma cultura de paz na sociedade.

Pelo menos três teorias contemporâneas da educação consubstanciam a proposta anterior, a primeira delas é a Teoria Tecnológica, que, tanto no design quanto no conteúdo, apresentado em diferentes tipos de mídias e hipermídias em uma infinidade de recursos existentes no campo virtual(local em que a maioria dos alunos encontra-se completamente inseridos), indicam que a aprendizagem em $\mathrm{DH}$ no ensino médio pode ser melhor conduzido se apresentado de forma mais lúdica e tecnológica.

No entanto, Bertrand (2001, p. 119) destaca um paradoxo observado dentro da Teoria Tecnológica que pode explicar a resistência dos professores em inserir mais tecnologia na sua prática escolar, o que se evidencia ao remontarmos as expectativas do docente quando do início do desenvolvimento tecnológico no campo educacional. Naquele momento, os professores acreditavam que a tecnologia aumentaria seu "controle" sobre o processo educativo, mas, foram surpreendidos com a "sensação" de que o desenvolvimento acelerado da tecnologia na verdade tirava o controle destes mesmos professores sobre o ato educativo e passava para os teóricos e técnicos da informática, ao passo que, confirmou-se mais a frente, que o resultado do desenvolvimento tecnológico no campo educacional devolveu ao estudante o "poder", o "controle" sobre o seu individual processo educacional. Portanto, a resistência em parte do magistério em deixar que a linguagem tecnológica ensine ao mesmo tempo professores e 


\section{alEducitec \\ ISSN: 2446-774X}

alunos, parte da discussão sobre o "o poder" no processo educativo. Se o professor abre mão deste "poder" ele pode propiciar o aprendizado coletivo, crescendo e descobrindo junto aos seus alunos sobre a temática proposta, conduzindo e se deixando conduzir pela linguagem atual da nova geração, a linguagem tecnológica.

Somado a teoria tecnológica do aprendizado, o uso de ferramentas tecnológicas no campo educacional, notadamente, nas questões de Direitos Humanos se justifica também através das Teorias Sociocognitivas, ou, mais precisamente da Teoria do Conflito Cognitivo, segundo a qual a chave do desenvolvimento, do aprendizado individual são as confrontações interindividuais (BERTRAND, 2001, p. 127), assim, o diálogo orientado entre estudantes e professores sobre temas relativos aos Direitos Humanos é que ajudará na construção do conhecimento, que é necessariamente social. Neste ponto, a aprendizagem é alcançada através da soma do conflito entre diferentes pontos de vista do coletivo, além do que, o papel do professor facilitador é bastante destacado dentro desta teoria (BERTRAND, 2001, p. 145).

Por fim, as Teorias Sociais fortalecem o modelo de aprendizagem defendido na transversalidade do ensino/aprendizagem de $\mathrm{DH}$ na educação básica, com destaque para os objetivos da educação que deve se assentar em mudanças da sociedade para melhor, motivo pelo qual torna-se imprescindível um maior enfrentamento dos assuntos pertinentes. Com base em Paulo Freire, entender também que o diálogo em sala é fundamental à comunicação, ao contrário do silenciamento, que o autor chama de antidiálogo, pelo qual um dos polos domina o outro, a pedagogia da comunicação seria uma inciativa para vencer estes antidiálogos ou a troca de insultos, comuns nas redes sociais, que igualmente nos parece um obstáculo para que ocorra um verdadeiro diálogo. (BERTRAND, 2001, p.160).

Temas comuns relacionados aos direitos humanos tais como, negros, desigualdades sociais, meio ambiente, mulheres e gênero devem ser debatidos na escola, já que permeiam a existência do estudante dentro e fora da instituição. Pensar sobre estes temas através de outras fontes que não somente o professor, encontrar paralelos entre o tratamento destes temas em diferentes partes do mundo, ora muito igualitárias, ora declaradamente discriminatórios ajuda 0 estudante e o professor a compreenderem melhor a temática e situar seu tratamento no contexto no qual o Brasil se insere.

Há conteúdos bons e instrutivos disponíveis livremente nas gigantes redes sociais e dispersos em toda a internet, a escolha deste tipo de acervo para tratar de importantes e multifacetados assuntos que envolvam Direitos Humanos tem total relação com o público ao qual o professor pretende comunicar-se, alunos do ensino médio, em sua maioria adolescentes e jovens. O contexto social dos estudante e os problemas sociais que eles enfrentam devem ser levados em consideração para a escolha do material, e, modo geral, o uso da tecnologia, se direcionada para o campo educacional pode fomentar aprendizado sobre Direitos Humanos de forma lúdica, atual e tecnológica. Com isto, não só os alunos, mas também os professores irão se familiarizar com o tema mais facilmente. Ademais, há a possibilidade dos docentes utilizarem este momento 


\section{Educitec \\ ISSN: $2446-774 X$}

de "livre navegação" pela rede para estimular nos discentes a autonomia e criar estratégias que desenvolvam o discernimento crítico ao coletar e analisar as informações disponíveis.

Ao final, tudo se resume em "poder" em "controle" sobre o ato educativo, se professor abrir mão de ser o controlador do processo de aprendizagem dos seus alunos é que se dará o processo inovador da educomunicação. Assim, o docente poderá aprender e ensinar, concomitantemente, sobre Direitos Humanos, lançando-se também como um aprendiz, um facilitador, um orientador e mediador dos conflitos e por fim, dar sentido, significado à educação, qual seja, ajudar os alunos a um melhor enfrentamento da vida social, talvez um dos mais relevantes problemas o nosso tempo.

\section{A educomunicação e o ensino/aprendizagem de Direitos Humanos}

Para tratar de Educomunicação na escola - uma abordagem que de certa forma mistura educação e comunicação - é preciso refletir sobre um dos autores mais expoentes deste modelo de comunicação educacional, o professor Ismar de Oliveira Soares, que, desde a década de 1970 escreve e atua com educomunicação no Brasil:

Ao denominar a Educomunicação, a modalidade latino-americana de se analisar e produzir comunicação numa perspectiva dialógica e dialética, visando ampliar o coeficiente comunicativo das ações humanas, no contexto de ecossistemas comunicacionais democráticos e participativos, voltados à prática plena da cidadania, nos vimos diante de uma demanda prática urgente: levar o conceito e sua filosofia a setores fortemente estruturados, como o da educação formal. (...) Em síntese, voltando à pergunta, posso adiantar que a especificidades do conceito que propomos remete à noção do campo emergente de práticas sócias, na interface entre a Comunicação e a Educação e que, para além da formação de audiências críticas em relação aos meios de informação, forma cidadãos que têm na comunicação e em sua gestão democrática um paradigma norteador de suas ações, em benefício de toda a comunidade onde sejam inseridos (ROVIDA, 2017, p. 388-389).

É sobre este conceito de educomunicação que assentamos a base do pensamento que propõe estudar/discutir Direitos Humanos no ensino médio usando recursos tecnológicos adequados, em benefício do melhor aproveitamento do tema, da incitação à curiosidade dos adolescentes e jovens e da maior capacidade de diálogo entre alunos e professores, no que tange a assuntos tão complexos e que demandam análise de diferentes pontos de vista. Neste sentido, o professor Ismael alerta para que a Educomunicação não seja vista apenas como uma "alternativa didática", mas que seja sim um paradigma conceitual aplicado tanto a professores quando a alunos, dentro e fora do sistema formal de ensino, sendo certo que o que definirá o uso da tecnologia não é a ferramenta em si mas, os objetivos e as metodologias que se deseja ensinar e sejam coerentes com esta nova prática (RODOVIDA, 2017, p. 392).

A meta de que a educação dê conta da promoção do respeito ao outro, mediante o desenvolvimento de múltiplas linguagens, tendo como base a compreensão da 


\section{Eteducitec}

ISSN: 2446-774X

democracia, vem sendo discutida na elaboração da Base Nacional Comum Curricular do Ensino Médio (MEC, 2016) o que sinaliza no sentido de um maior reconhecimento da presença de elementos da educomunicação na trajetória formativa do aluno, instando a nos perguntar se, de fato, a aproximação entre a comunicação e a educação pode responder aos desafios de uma sociedade do nosso tempo, em termos de comunicação e informação. As discussões no campo político educacional para o redesenho curricular da educação básica nos dão indícios de que a resposta parece ser afirmativa, na área de linguagem é oportuna a seguinte reflexão:

Ainda que a Educomunicação se reconheça como um campo transdisciplinar de conhecimento e de intervenção social, com possibilidades de convivência com as quatro áreas de conhecimento, interessa-nos, por uma questão metodológica, um olhar específico sobre o diálogo com a área de linguagens, pois cabe a esta tratar especificamente dos conhecimento relativos à atuação dos sujeitos em variadas esferas da comunicação humana, das mais cotidianas às mais formais e elaboradas. São conhecimentos que - segundo o projeto - "possibilitam mobilizar e ampliar recursos expressivos para construir sentidos com o outro em diferentes campos de atuação, além e propiciar a compreensão de como o ser humano se constitui como sujeito e como age no mundo social em interações mediadas por palavras, imagens, sons, gestos e movimentos (SOARES, 2016, p. 18).

No campo das ciências, uma ponderação sobre as dificuldades do ensino de Direitos Humanos na educação básica e a sua contribuição para a formação da cidadania são conflitos que igualmente permeiam o tema:

O outro aspecto que parece ser um obstáculo para uma aproximação das relações entre ciência, tecnologia e sociedade na sala de aula é o receio que muitos professores têm, em particular os de ciências, de discutir temas relacionados com valores. Opiniões políticas, formas de se encarar as conexões da ciência com as ideologias (por exemplo, a capitalista), possíveis divergências com valores familiares, certos preconceitos (ideológicos/religiosos), pontos de vista radicais, etc., tudo isso leva o professor de ciência a fugir da discussão e manter suas aulas em patamares seguros - 0 da ciência considerada como neutra. Em geral, e penso que isso faça parte da tradicional formação profissional-cultural do professor, nenhum ou quase nenhum deles se sente à vontade quando o tema da aula não faz parte de um conteúdo conceitual previsto. Raramente o professor aprecia o debate aberto, imprevisível. Por isso, as discussões sobre os diversos pontos de vista dos estudantes acerca dos significados éticos, políticos e sociais da ciência e da tecnologia são naturalmente eliminados da sala de aula. No entanto, todos sabem que os novos objetivos para o ensino de Ciências envolvem o debate e exigem, para tanto, educadores abertos, dispostos a questionar com seus alunos o lugar da ciência no mundo, sua relação com o bem-estar humano e com outros valores da sociedade (SANTOS, 2006, p. 3).

Enfim, a discussão não se encerra nela mesma, mas, haja vista a atual construção da base curricular nacional do ensino médio é oportuno pensarmos formas de efetivação do aprendizado sobre direitos humanos nesta etapa escolar, um diálogo que deve ouvir discentes, docentes e pais, mas, mais do que tudo deve estar atendo a novas formas de aprendizagem, que respondam aos interesses dos alunos, sob pena da sonhada transversalidade do tema no ensino 


\section{Edecitec \\ ISSN: 2446-774X}

médio se mantenha em temas pontuais que atendam ao mínimo, a possível cobrança do assunto no vestibular.

\section{Considerações finais}

Rediscutir a trajetória formativa dos alunos da educação básica, notadamente do ensino médio, não tem sido tarefa fácil, mas, o contexto de violência e intolerância que estamos socialmente vivenciando, dentro e fora dos limites da escola, nos obriga a encontrar outros caminhos para o exercício da cidadania. Isso implica muito mais em conhecer direitos e deveres cívicos, compreende o apoderamento dos conceitos historicamente construídos sobre Direitos Humanos, advindo de lutas e organização social.

Pensar a escola como única instância capaz de minimizar os conflitos sociais é ter ingenuidade na busca de soluções para a promoção de uma cultura de paz e para encontrar um sentido claro para a escolarização. Mas, silenciar a escola sobre temas delicados de direitos humanos, como tenta implementar por meio de leis o programa escola sem partido, é sem dúvidas diminuir a capacidade que a educação formal tem de promover uma formação emancipadora, cidadã, que reconhece 0 direito à igualdade ao mesmo tempo que respeita o direito à diferença.

Conceitos de educomunicação, sustentado por diversas teorias contemporâneas de aprendizagem, como a tecnológica, a social e a sociocognitiva dão sustentação à defesa de um Ensino Médio empoderador, que, mais que ensinar sobre Direitos Humanos dialoga sobre o tema, respeita e conhece novos argumentos, enfim, permite ao professor, aquele que de fato conseguir se despir do controle sobre o processo de aprendizagem dos seus alunos, pelo menos nos temas afetos aos Direitos Humanos, permitirá ao docente aprender ao mesmo tempo que ensina, e, junto aos alunos, em posição de igualdade, serem protagonistas da construção de uma sociedade mais justa e promotores de uma sonhada sociedade de paz.

\section{Referências}

BRASIL, Secretaria de Direitos Humanos da Presidência da República. Educação em Direitos Humanos: Diretrizes Nacionais. Brasília: Coordenação Geral de Educação em SDH/PR, Direitos Humanos, Secretaria Nacional de Promoção e Defesa dos Direitos Humanos, 2013. Disponível em: $<$ http://portal.mec.gov.br/index.php?option=com_docman\&view=download\&alia $\mathrm{s}=32131$-educacao-dh-diretrizesnacionais-pdf\&Itemid=30192>. Acesso em: 14 nov 2017.

BRASIL. Lei de Diretrizes e Bases da Educação Nacional - n 9.394. 1996. Disponível em: <http://www.planalto.gov.br/ccivil_03/Leis/L9394.htm>. Acesso em: 19 set 2017.

BERTRAND, Yves. Teorias Contemporâneas da Educação. 2 ed. Tradução Alexandre Emílio. Lisboa: Instituto Piaget, 2001. 


\section{Ededucitec \\ ISSN: $2446-774 X$}

CÂMARA DOS DEPUTADOS. Projeto de Lei 867/2015 (Escola sem partido). Disponível em $<$ http://www.camara.gov.br/proposicoesWeb/fichadetramitacao?idProposicao=1 050668>. Acesso em: 13 nov 2017.

CANDAU, Vera Maria. Direitos Humanos, educação e interculturalidade: as tensões entre igualdade e diferença. Revista Brasileira de Educação, 2008. Disponível em: <http://www.scielo.br/pdf/rbedu/v13n37/05.pdf >. Acesso em: 28 nov 2017.

MEC. Base Nacional Comum Curricular. 2017. Disponível em: <http://basenacionalcomum.mec.gov.br/images/BNCC_publicacao.pdf>.

Acesso em: 13 out 2017.

MEC. Base Nacional Comum Curricular. 2º versão. 2016. Disponível em: <http://historiadabncc.mec.gov.br/documentos/bncc-2versao.revista.pdf>.

Acesso em: 13 de out 2017.

MORIN, Edegar. Cabeça Bem- Feita - repensar a reforma - reformar o pensamento. 2003.2 Disponível em: <http://www.uesb.br/labtece/artigos/A\%20Cabeça\%20Bem-feita.pdf>. Acesso em: 01 nov 2017.

RAMOS, Marise Nogueira. O currículo para o ensino médio em suas diferentes modalidades: concepções, propostas e problemas. 2011. Educ. Soc., Campinas, v. 32, n. 116, p. 771-788, jul.-set. 2011. Disponível em: $<$ http://www.cedes.unicamp.br/publicacoes/edicao/67>. Acesso em 22 nov. 2017.

RAMOS, Marise. Ensino Médio Integrado: Ciência, trabalho e cultura na relação entre a educação profissional e educação básica. In: MOLL, Jaqueline (Org.). Educação Profissional e tecnológica no Brasil contemporâneo - desafios, tensões e possibilidades. Porto Alegre: Artmed, 2010, p. 49-57.

RAMOS, Marize. Concepção de Ensino Médio Integrado. 2008. Fonte: https://tecnicadmiwj.files.wordpress.com/2008/09/texto-concepcao-do-ensinomedio-integrado-marise-ramos1.pdf. Acesso em 21 set 2017.

ROVIDA, Mara. Educomunicação, uma prática social: entrevista com Ismar de Oliveira Soares. 2017. Disponível em:

<periodicos.uniso.br/ojs/index.php/reu/article/download/3133/2797>. Acesso em: 12 jul 2018.

SANTOS, Paulo Roberto dos. O Ensino de Ciências e a Ideia de Cidadania. 2006. Disponível em: <http://www.hottopos.com/mirand17/prsantos.htm>. Acesso em: 24 de jun 2018.

SAVIANI, D. Trabalho e educação: fundamentos ontológicos e históricos. Revista Brasileira de Educação, v. 2, jan/abr 2007. p. 152 - 180.

SOARES, Ismar de Oliveira. Educomunicação possível: uma análise da proposta curricular do MEC para o Ensino Básico. Comunicação \& Educação. Ano XXI, número 1, jan. 2016. Disponível em $<$ http://www.revistas.usp.br/comueduc/article/view/110451 >. Acesso em: 19 jun. 
2018.

Submetido em 03/08/2018.

Aceito em 26/02/2019.

(c) (†) 